\title{
VIOLENCIA DE GÉNERO: POLÍTICAS PÚBLICAS, DEFENSA DEL DERECHO FUNDAMENTAL A LA NO DISCRIMINACIÓN Y PROPUESTAS DE SOLUCIÓN
}

\author{
GENDER VIOLENCE: PUBLIC POLICIES, UPHOLDING THE \\ FUNDAMENTAL RIGHT TO NON-DISCRIMINATION AND PROPOSED \\ SOLUTIONS
}

Bruno Novoa Campos ${ }^{1}$

\section{Resumen}

El autor considera que las diferentes manifestaciones que presenta la violencia de género se deben analizar desde las políticas públicas establecidas por el Estado peruano y su defensa se debe centrar en el fortalecimiento del derecho fundamental a la no discriminación. Propone la creación de la Secretaría Técnica de Defensa de la Mujer.

Palabras claves discriminación, violencia de género, políticas públicas.

\section{Abstract}

The author believes that the different forms of gender violence should be analyzed in light of the public policies established by the Peruvian State and its defense should focus on strengthening the fundamental right to non-discrimination. The author proposes creating the Technical Secretariat of Defense of Women's Rights.

Keywords: Discrimination, Gender Violence, Public Policies.

SUMARIO: I. DELIMITACION; II. POLÍTICAS PÚBLICAS; III. PRINCIPALES MANIFESTACIONES; IV. DEFENSA DEL DERECHO FUNDAMENTAL A LA NO DISCRIMINACION; V. A MANERA DE CONCLUSIÓN

Director Académico de la Academia de la Magistratura. Docente de Derecho Constitucional de la Universidad Femenina del Sagrado Corazón - UNIFE. 


\section{DELIMITACIÓN}

Debemos partir delimitando adecuadamente el concepto de violencia de género. Ello, debido a que se relaciona directamente la violencia de género con la violencia contra la mujer.

En tal sentido, acorde a lo establecido por la ONU Mujeres -entidad de la ONU para la igualdad de género y el empoderamiento de la mujer- la violencia basada en género se refiere a aquella violencia dirigida contra una persona en razón del género que él o ella tiene; así como, de las expectativas sobre el rol que él o ella deba cumplir en una sociedad o cultura. ${ }^{2}$

Mientras que la "violencia contra las mujeres" es todo acto de violencia basado en la pertenencia al sexo femenino que tenga o pueda tener como resultado un daño o sufrimiento físico, sexual o psicológico para la mujer, así como las amenazas de tales actos, la coacción o la privación arbitraria de la libertad, tanto si se producen en la vida pública como en la vida privada ${ }^{3}$.

Es decir, al referirnos a la violencia de género nos estaremos refiriendo a la violencia que se presenta contra varones y damas, sin diferenciar edades ni tampoco motivo por origen, raza, sexo, idioma, religión, opinión, condición económica o de cualquiera otra índole (artículo 2, numeral 2 de la Constitución Política del Perú - en adelante, la CPP).

Sin embargo, como apreciaremos más adelante, acorde a las actuales circunstancias y al alto índice de violencia contra la mujer, la normativa nacional, los compromisos internacionales y la política pública peruana ha centrado su interés en la defensa de la mujer. ${ }^{4}$

\section{POLÍTICAS PÚBLICAS}

Uno de los principales objetivos de este artículo es el de poder analizar las diferentes manifestaciones de la violencia de género desde las políticas públicas. Consideramos que no tiene sentido analizar las manifestaciones de la violencia de género si no se cuenta con un marco nacional que establezca acciones claras para dar solución a este gran problema nacional.

Disponible en el siguiente link web: http://www.endvawnow.org/es/articles/295-defining-violence-against-women-and-girls.html Consultado el 02 de agosto de 2016.

Resolución de la Asamblea General Resolución 48/104 Declaración sobre la eliminación de la violencia contra la mujer, 1993.

4 Disponible en el siguiente link web https://www.inei.gob.pe/estadisticas/indice-tematico/violencia-de-genero-7921/ Consultado el 02 de agosto de 2016 
En este escenario, son 2 los planes del Estado peruano que son los que sobre todo consideramos pertinente analizar.-aunque existen otros de manera transversal o de carácter público-privada.

Nos referimos al Plan Nacional de Igualdad de Género 2012-2021, aprobado mediante Decreto Supremo No 004-2012-MIMP, denominado PLANIG y que es el instrumento cuyo objetivo es transversalizar el enfoque de género en las políticas públicas del Estado Peruano.

Asimismo, es importante rescatar, el Plan Nacional contra la violencia de género, aprobado mediante Decreto Supremo № 008-2016-MIMP, cuyo principal objetivo es el de la prevención, sanción y erradicación de la violencia de género.

Ambos planes se enmarcan en las acciones afirmativas ${ }^{5}$ que realiza el Estado peruano para enfrentarse a la violencia de género.

Al respecto, el Tribunal Constitucional peruano (en adelante, el TC), en la sentencia recaída en el Exp. $\mathrm{N}^{\circ}$ 05652-2007-PA/TC, destaca la importancia de las acciones afirmativas frente a la violencia de género. A continuación, se aprecian los fundamentos jurídicos más resaltantes:

\section{“(...)}

26. De otra parte conviene destacar que en el Art. 4 de la CEDM se reconoce que la igualdad jurídica de la mujer no garantiza automáticamente su trato en igualdad de condiciones, por lo que para acelerar la igualdad real de la mujer en la sociedad y en el lugar de trabajo, los Estados pueden aplicar medidas positivas de carácter correctivo mientras persistan las desigualdades.

27. En el caso de las mujeres las acciones positivas constituyen medidas (normas jurídicas, políticas, planes, programas y prácticas) que permiten compensar las desventajas históricas y sociales que impiden a las mujeres y a los hombres actuar en igualdad de condiciones y tener las mismas oportunidades, es decir, que tienen la finalidad de conseguir una mayor igualdad social sustantiva. En tal linea, el Tribunal Constitucional, en la STC $N^{o}$ 0001/0003-2003-AI/TC, ha destacado que es deber del Estado ser el promotor de la igualdad sustancial entre los individuos mediante "acciones positivas" o "de discriminación inversa".

Para el TC, en la sentencia recaída en el Exp. № 0048-2004-AI/TC, fj. 63 “(...) Debe tenerse en consideración que el estado en algunas oportunidades promueve el trato diferenciado de un determinado grupo social, otorgándoles ventajas, incentivos o, en general tratamientos más favorables. Esto es lo que en doctrina constitucional se conoce como "discriminación positiva o acción positiva -affirmative action". La finalidad de esta acción afirmativa no es otra que compensar jurídicamente a grupos marginados económica, social o culturalmente; persigue, pues, que dichos grupos puedan superar la inferioridad real en la que se encuentran con acciones concretas del Estado." 
28. En igual sentido, la Corte Interamericana de Derechos Humanos ha señalado que ciertas desigualdades de hecho "legitimamente pueden traducirse en desigualdades de tratamiento jurídico, sin que tales situaciones contraríen la justicia". Ello debido a que "pueden ser un vehículo para realizarla o para proteger a quienes aparezcan como jurídicamente débiles".

29. Por lo tanto, la prohibición internacional de discriminación basada en el sexo busca promover la igualdad real de las mujeres. Acorde con este propósito, el Estado peruano ha asumido la obligación de adoptar todas las medidas necesarias para aplicar el principio de la igualdad entre el hombre y la mujer o para remover los obstáculos que impiden el ejercicio pleno del derecho a la igualdad; de dar a las mujeres oportunidades de entablar acciones y pedir protección frente a la discriminación; de tomar las medidas necesarias para eliminar la discriminación tanto en la esfera pública como en el ámbito privado; y de adoptar medidas de acción positiva para acelerar la igualdad de hecho entre el hombre y la mujer. $(\ldots)^{\prime \prime}$

En tal sentido, teniendo en consideración la importancia de las acciones afirmativas del Estado peruano para enfrentar a la violencia de género, sugeriremos, a continuación, respetuosamente algunas políticas públicas que deberían ejecutarse para enfrentar las principales manifestaciones de la referida violencia.

\section{PRINCIPALES MANIFESTACIONES}

Acorde a lo establecido en el Plan Nacional contra la violencia hacia la mujer 2009-2015 publicado por el Ministerio de la Mujer y Poblaciones Vulnerables -en adelante, el MIMP- la violencia hacia la mujer presenta 3 principales manifestaciones:

\subsection{Violencia familiar}

La primera, es la referida a la violencia familiar. Para el MIMP la violencia familiar es cualquier acción u omisión que cause daño físico, psicológico, maltrato sin lesión, inclusive la amenaza o coacción graves, que se produzcan entre cónyuges, convivientes, o parientes, quienes habitan en el mismo hogar.

Al respecto, podemos analizar el referido concepto desde diferentes aristas:

- Uno de los aspectos más importantes del referido concepto es el hecho de que no limita la violencia familiar a la violencia que se presenta entre 
cónyuges. En efecto, la violencia familiar también puede manifestarse entre convivientes y parientes que habitan el mismo hogar.

- El otro aspecto que debemos rescatar es el hecho de que la referida violencia no necesariamente tiene que ser progresiva o gradual, es decir, no necesariamente debe pasarse de violencia psicológica a una violencia con amenaza, de una violencia con amenaza a un maltrato sin lesión, de un maltrato sin lesión a un maltrato con lesión así sucesivamente hasta llegar a un maltrato físico (o alguna otra variante).

La violencia familiar simplemente se configura al manifestarse alguno de estos elementos.

Asimismo, en la violencia familiar pueden confluir varios de estos elementos. Así por ejemplo, es claro que al manifestarse una amenaza confluye de forma conjunta una violencia psicológica. Ninguna mujer se queda psicológicamente estable al recibir una amenaza.

De igual modo, al configurarse, por ejemplo, un maltrato con lesión es muy probable que el agresor amenace a su víctima con volverlo a realizar. Además, claro, de configurarse una violencia psicológica.

- Otro aspecto de importante valor es el hecho de que la violencia familiar no necesariamente deba permanecer en el tiempo. Es decir, la violencia psicológica, por ejemplo, no debe darse todos los días o de forma inter-diaria para considerar que se ha manifestado este tipo de violencia.

Bastará que se presente la violencia familiar en una sola oportunidad para que se configure el hecho. Sin embargo, en la práctica muchos de los cónyuges, convivientes o familiares, más que todo por aspectos culturales, buscan solucionar este "impase" esperando próximas reuniones familiares para "conversarlo".

El problema de este tipo de solución se presenta cuando la violencia familiar es mayor a la ocasionada en el marco de una, por ejemplo, discusión acalorada en el seno familiar. Asimismo, el problema de este tipo de solución se presenta cuando se ha ejercido una violencia indirecta.

- La violencia familiar indirecta es aquella violencia que se ejerce frente a un pariente que no teniendo relación directa en la amenaza o acción presencia la misma y es indirectamente afectada. Caso claro de este tipo de violencia familiar indirecta es el de los parientes menores que presencian la discusión de los mayores, observan violencia psicológica, amenazas e incluso violencia 
física; pudiendo pasar, de sujetos pasivos de la acción a sujetos activos de la misma -muchas veces los menores salen en apoyo de su familiar y son también víctimas de maltrato-

- Un último aspecto a considerar, es el hecho del consentimiento de la violencia familiar. El consentimiento de la violencia familiar se puede manifestar por diversas razones: por desconocimiento, por cuestiones culturales, por vergüenza social, por encontrarse bajo un estado de amenaza, por presión familiar, entre otros.

\subsection{Violencia sexual}

La segunda manifestación es la violencia sexual. Por violencia sexual el MIMP entiende a todo acto sexual, tentativa, comentarios o insinuaciones sexuales, no deseados, o acciones para comercializar o utilizar de cualquier otro modo la sexualidad de una persona mediante coacciones por otra persona, independientemente de la relación de ésta con la víctima.

Al respecto, podemos manifestar:

- El concepto que brinda el MIMP involucra no solo el acto en si -que es lo que comúnmente se relaciona a la violencia sexual- sino los comentarios o insinuaciones sexuales.

Al respecto, hay que advertir que son justamente estos comentarios e insinuaciones sexuales los que se manifiestan en diferentes espacios, sin importar la edad e incluso el medio.

En efecto, los comentarios e insinuaciones sexuales se manifiestan en diferentes espacios: i) pueden ser en espacios públicos (conciertos, discotecas, bares, otros); y, ii) espacios privados (reuniones o aniversarios laborales, colegio, universidad, instituto, otros).

La violencia sexual también se manifiesta en comentarios e insinuaciones sin importar la edad. Si bien es cierto, los espacios públicos o privados son los escenarios iniciales para que se presente este tipo de violencia, las relaciones interpersonales no diferencian edad, toda vez que hay mujeres que aparentan una edad cuando en verdad son menores de edad; y cuando se presentan formalmente por medio de algún conocido común -si es que diera esa oportunidad- puede ya haber existido algún tipo de insinuación sexual.

De igual forma, los comentarios y las insinuaciones sexuales son más recurrentes en los medios virtuales; las redes sociales son el sitio ideal para 
que se presenten este tipo de hechos. Se pueden crear "falsos perfiles" para captar menores de edad e iniciar con las insinuaciones e incluso comentarios.

- Asimismo, el concepto considera la posibilidad de la comercialización. Al respecto, confluyen varias posibilidades para que ello suceda.

En principio, la posibilidad de que sea el propio usuario el que por sus propios medios comparta imágenes que después puedan ser comercializados sexualmente.

Otra posibilidad es el hecho de que, aprovechando el uso de la tecnología, se utilicen imágenes que no necesariamente contengan contenido sexual pero que puedan ser "manipuladas" para tal fin.

Finalmente, aunque ello no obsta otras posibilidades, se encuentra el hecho de que existen personas naturales dedicadas a este rubro así como organizaciones criminales que lucran con este tipo de violencia sexual.

\subsection{Feminicidio}

Finalmente, para el MIMP el feminicidio contempla la tercera manifestación. Se conoce como feminicidio a aquellos homicidios de mujeres en condiciones de discriminación y violencia basada en género.

Esta es sin duda, la manifestación más extrema y que cuenta con un trasfondo que debe analizarse desde diferentes aspectos:

- Es cierto que los homicidios contra mujeres causan gran pena a los familiares y allegados de la víctima; también es cierto que se deben investigar las causas y dar con el responsable a fin de que el homicidio no quede impune, pero también es cierto que este tipo de homicidios se da teniendo como móvil la discriminación y violencia basada en género; lo cual si es sumamente preocupante.

El hecho que se consume un homicidio por discriminar a una mujer configura un trasfondo bastante peligroso. Consideramos que en principio debe analizarse al sujeto causante de esta acción, porque es muy probable que haya tenido diferentes taras en su formación que lo hayan llevado a pensar que las mujeres que lo rodean son inferiores a él y que pueden ser objeto de agresión e incluso, de causarles la muerte.

Este primer análisis es importante ya que es probable que se pueda llegar al círculo más cercano del agresor -y que posiblemente tengan una formación 
similar-, con lo que el Estado pueda tener muchas más posibilidades para intervenir y sobre todo prevenir actos similares.

Un segundo punto de análisis involucra a las acciones a realizar desde la educación y en todos sus niveles. La imagen discriminatoria no se forma en un solo momento, es una imagen que va acompañando a las personas durante varias etapas de su vida, especialmente en la primera infancia. Desde la división de grupos entre varones y mujeres, desde la selección de ropa (azul para los varoncitos y rosado para las mujercitas) se va marcando una imagen discriminatoria en las personas.

Una última circunstancia, aunque pueden existir muchas más razones, para que se llegue al extremo de matar a una mujer por discriminación, es el hecho de que la propia sociedad lo fomenta.

Sin duda, la televisión, las series de televisión, los videos en canales sociales, las novelas, muestran -no siempre pero en muchas ocasiones- escenas cercanas a la muerte o donde se da muerte a las mujeres por parte del cónyuge, el conviviente, el amante, el pariente u otro varón.

Lo particular de estas escenas es el hecho de que no todas las personas lo reflexionan de la misma manera, la escena de la muerte de una mujer por parte de un varón -o incluso de otra mujer- puede ser asumida para un preadolescente o adolescente como una escena cercana a la realidad; más aún, si vive en un entorno poco favorable para su crecimiento emocional o que no le permita alcanzar cierta madurez mental donde pueda discernir lo real de lo fantasioso.

\section{DEFENSA DEL DERECHO FUNDAMENTAL A LA NO DISCRIMINACIÓN}

Teniendo en consideración la importancia de las acciones afirmativas del Estado peruano frente a la violencia de género así como, algunas propuestas para hacer frente a sus principales manifestaciones, es importante iniciar una adecuada defensa constitucional ante este tipo de violencia. En tal escenario, si bien es cierto el Congreso de la República y el Poder Ejecutivo han venido impulsando diversas leyes, decretos supremos y directivas sobre el particular ${ }^{6}$ así como, se ha tenido en consideración los

6 - Ley para prevenir, sancionar y erradicar la violencia contra las mujeres y los integrantes del grupo familiar-Ley- $\mathrm{N}^{\circ}$ 30364. Publicada el 23 de noviembre de 2015, en el Diario Oficial "El Peruano".

- Ley de Igualdad de Oportunidades entre Mujeres y Hombres - Ley №2 28983, publicada el 16 de marzo de 2007, en el Diario Oficial "El Peruano".

- Ley Orgánica del Poder Ejecutivo - Ley № 29158, publicada el 20 de diciembre de 2007, en el Diario Oficial “El Peruano". 


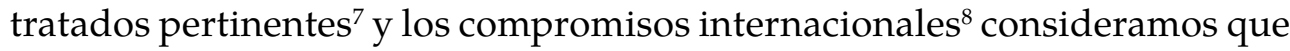 la defensa que se debe de realizar para hacer frente a este tipo de violencia no puede ser menor que una defensa constitucional. Específicamente una defensa del derecho fundamental a la no discriminación.
}

\author{
- Ley de Organización y Funciones del Ministerio de la Mujer y Poblaciones Vulnerables - Decreto Legislativo № \\ 1098, publicada el 20 de enero de 2012, en el Diario Oficial "El Peruano". \\ - Ley Orgánica de Gobiernos Regionales - Ley № 27867, publicada el 18 de noviembre de 2002 y sus modificatorias, \\ en el Diario Oficial "El Peruano". \\ - Ley Orgánica de Municipalidades - Ley № 27972, publicada el 27 de mayo de 2003, en el Diario Oficial “El Perua- \\ no".
}

- Ley General del Sistema Nacional de Presupuesto - Ley № 28411, publicada el 08 de diciembre de 2004 y sus modificatorias, en el Diario Oficial "El Peruano".

- Ley de Partidos Políticos - Ley № 28094, publicada el 01 de noviembre de 2003, en el Diario Oficial “El Peruano". - Ley de Fomento de la Educación de las Niñas y Adolescentes Rurales - Ley № 27558, publicada el 31 de octubre de 2001, en el Diario Oficial "El Peruano".

- Ley que fomenta la reinserción escolar por embarazo - Ley $\mathrm{N}^{\circ} 29600$, publicada el 15 de octubre de 2010, en el Diario Oficial "El Peruano".

- Texto Único Ordenado de la Ley № 26260, Ley de Protección contra la Violencia Familiar, publicado el 27 de junio de 1997, en el Diario Oficial "El Peruano".

- Ley de Prevención y Sanción del Hostigamiento Sexual- Ley № 27942, publicada el 27 de febrero de 2003 y sus modificatorias, en el Diario Oficial "El Peruano".

- Ley que modifica el artículo 107 del Código Penal, incorporando el feminicidio - Ley № 29819, publicada el 27 de diciembre de 2011, en el Diario Oficial "El Peruano".

- Ley contra la Trata de Personas y el Tráfico Ilícito de Migrantes - Ley № 28950, publicada el 16 de enero de 2007 y su Reglamento el D.S. № 007-2008-IN, publicado el 30 de noviembre de 2008, en el Diario Oficial “El Peruano”, en el Diario Oficial "El Peruano".

- Ley que concede el derecho de licencia por paternidad a los trabajadores de la actividad pública y privada, Ley № 29409, publicada el 20 de septiembre de 2009, en el Diario Oficial "El Peruano".

- Ley de los trabajadores del hogar - Ley № 27986, publicada el 03 de junio de 2003, en el Diario Oficial "El Peruano". - Ley que incluye el trabajo no remunerado en las cuentas nacionales - Ley № 29700, publicada el 04 de junio de 2011, en el Diario Oficial "El Peruano".

- Ley que modifica el artículo 2 de la Ley № 28457, Ley que regula el proceso de filiación judicial de paternidad extramatrimonial - Ley № 29715, publicada el 21 de junio de 2011, en el Diario Oficial "El Peruano".

- La Directiva № 001 - 2011- EF 50.01, "Para la programación y formulación del presupuesto del Sector Público", aprobada por Resolución Directoral № 002- 2011-EF/50.01, publicada el 09 de junio de 2011, en el Diario Oficial “El Peruano", cuyo artículo 38 dispone "que los diversos niveles de gobiernos y sectores, en el marco de la Ley № 28983 y la Ley $\mathrm{N}^{\circ} 29083$, deben identificar brechas de género como un criterio que permita determinar la asignación de recursos para el logro de sus objetivos institucionales".

- Decreto Supremo № 027-2007-PCM, publicado el 25 de marzo de 2007, en el Diario Oficial “El Peruano", que define y establece las Políticas Nacionales de obligatorio cumplimiento para las entidades del Gobierno Nacional, entre ellas la política de igualdad de hombres y mujeres.

- Decreto Supremo № 009-2006-MIMDES, publicado el 26 de agosto de 2006, en el Diario Oficial "El Peruano", dispone la implementación de lactarios en instituciones del Sector Público donde laboren veinte o más mujeres en edad fértil.

- Decreto Supremo № 004-2008-MIMDES, publicado el 04 de abril de 2008, en el Diario Oficial "El Peruano", precisa que los estatutos de todas las organizaciones jurídicas sin fines de lucro, deberán adecuarse a las normas de la constitución y de la le relativas a la igualdad jurídica del varón y la mujer.

- En términos de compromiso político con la igualdad de género, el Estado peruano adoptó en el año 2002, el Acuerdo Nacional, cuya décimo primera política de Estado establece la promoción de la igualdad de oportunidades sin discriminación.

7 - Pacto Internacional de Derechos Civiles y Políticos, aprobado por el Perú mediante Decreto Ley № 22128 el 28 de marzo de 1978, vigente desde el 28 de julio de 1978, que dispone el compromiso de los Estados Partes del Pacto de garantizar a hombres y mujeres la igualdad de goce de todos los derechos civiles y políticos enunciados en el mismo. El Protocolo Facultativo del Pacto Internacional de Derechos Civiles y Políticos firmado por el Perú el 11 de agosto de 1977 y ratificado el 3 de octubre de 1980.

- Pacto Internacional de Derechos Económicos, Sociales y Culturales, aprobado por Decreto Ley № 22129 del 28 de marzo de 1978, vigente desde el 28 de julio de 1978, mediante el cual los Estados Partes se comprometen a garantizar el ejercicio a hombres y mujeres de los derechos económicos, sociales y culturales contenidos en el Pacto, como son el derecho a trabajar en condiciones equitativas y satisfactorias, a que las mujeres reciban protección durante un periodo razonable antes y después del parto.

- Convención sobre la Eliminación de Todas las Formas de Discriminación contra la Mujer - CEDAW y su Protocolo Facultativo, aprobada por Resolución Legislativa № 23432 del 04 de junio de 1982, vigente desde el 13 de octubre de 
La CPP ha dispuesto claramente que no existe discriminación por origen, raza, sexo, idioma, religión, opinión, condición económica o de cualquiera otra índole (artículo $2^{\mathrm{o}}$ numeral 2 ).

En tal sentido, consideramos que la defensa principal, desde el punto de vista constitucional, se debe centrar en la defensa a la no discriminación por sexo; discriminación por sexo la cual justamente subyace a la violencia de género.

Así, el TC en la sentencia recaída en el Exp. N 05652-2007-PA/TC, haciendo referencia a tratados sobre la materia, refuerza el hecho que sea la discriminación contra la mujer la que subyace a su violencia. A continuación, se aprecian los fundamentos jurídicos pertinentes:

1982, establece que los Estados Parte tomen medidas legislativas y administrativas necesarias para prevenir, investigar y castigar la discriminación hacia las mujeres. Propone una agenda de acción para erradicar tal discriminación que incluye la incorporación del principio de igualdad del hombre y de la mujer en sus sistemas legales.

- Convención Interamericana para Prevenir, Sancionar y Erradicar la Violencia contra la Mujer - Convención Belém Do Pará, aprobada mediante Resolución Legislativa № 26583 del 11 de marzo de 1996, reconoce que la violencia de género perpetrada o tolerada por los agentes de Estado o personas particulares constituye una grave violación a los derechos humanos y por lo tanto, los Estados tienen la responsabilidad de castigarla, prevenirla y erradicarla. - Estatuto de Roma de la Corte Penal Internacional, aprobado por Resolución Legislativa № 27517 del 16 de setiembre de 2001 y ratificado el 5 de octubre de 2001. Reconoce como crimen de lesa humanidad, la violación sexual, prostitución forzada, embarazo forzado, esterilización forzada o cualquier otra forma de agresión sexual de gravedad comparable, así como la esclavitud, el tráfico de personas en especial de mujeres y niños, siempre que los delitos enumerados consistan en un ataque generalizado contra una población civil. Con respecto a la composición de la Corte señala la necesidad de que exista representación equilibrada de magistrados mujeres y hombres.

- Convención de las Naciones Unidas Contra la Delincuencia organizada Trasnacional, incluyendo sus dos Protocolos Adicionales: Protocolo para Prevenir, Reprimir y Sancionar la Trata de Personas, especialmente Mujeres y Niños y el Protocolo Contra el Tráfico Ilícito de Migrantes por Tierra, Mar y Aire; los cuales han sido aprobados mediante Resolución Legislativa № 27527 del 8 de octubre de 2001. Establecen la obligación de los Estados de adoptar medidas adecuadas para prestar asistencia y protección a las víctimas de los delitos de trata de personas y tráfico ilícito de migrantes en particular en casos de amenaza de represalia o intimidad, para que obtengan indemnización y restitución. - Convenios de la Organización Internacional del Trabajo -OIT: Convenio 10072 sobre la igualdad de remuneración, 11173 sobre la discriminación (empleo y ocupación), 12274 sobre la política del empleo y 15675 sobre los trabajadores con responsabilidades familiares.

- Declaración de las Naciones Unidas sobre la Mujer Indígena, adoptada por la Comisión de la Condición Jurídica y Social de la Mujer en su 56º periodo de Sesiones: 27 de febrero a 9 de marzo de 2012.

8 - La Plataforma de Acción, adoptada en el marco de la Cuarta Conferencia Mundial sobre la Mujer, realizada en Beijing-China, 1995.

- Los Objetivos de Desarrollo del Milenio, aprobados en la Cumbre del Milenio de las Naciones Unidas del año 2000.

- Medidas clave para seguir ejecutando el Programa de Acción de la Conferencia Internacional sobre Población y Desarrollo (Cairo +5), adoptadas por consenso en el vigésimo primer período de sesiones de la Asamblea General de las Naciones Unidas. New York, 1999.

- Nuevas medidas e iniciativas para la aplicación de la Declaración y Plataforma de Acción de Beijing (Beijing +5), adoptada por la Asamblea General de las Naciones Unidas en su vigésimo tercer período extraordinario de sesiones. New York, junio 2000.

- Marco de Acción de Dakar "La educación para todos: cumplir con nuestros compromisos colectivos", adoptado en el Foro Mundial sobre la Educación. Dakar Senegal, abril 2000.

- Programa Interamericano sobre la promoción de los derechos humanos de la mujer y equidad e igualdad de género de la Comisión Interamericana de Mujeres-CIM de la OEA, adoptada por la Asamblea General del año 2000 y ratificada por los líderes del hemisferio en la Tercera Cumbre de las Américas.

- La Carta Democrática Interamericana, aprobada en Lima, Perú el 11 de Setiembre de 2001, durante el vigésimo octavo período extraordinario de sesiones de la Asamblea General de la OEA.

- Consenso de Quito, aprobado en la Décima Conferencia Regional de la Mujer de América Latina y el Caribe, realizada en Quito - Ecuador en el 2007.

- Consenso de Brasilia, aprobado en la Décima Primera Conferencia Regional sobre la Mujer de América Latina y el Caribe, CEPAL realizada en Brasil en el 2010. 


\section{"(...)}

22. La protección de la igualdad de derechos de la mujer ha sido ampliada y reforzada con la Declaración sobre la Eliminación de la Discriminación contra la Mujer (DEDM), la Convención sobre la Eliminación de todas las formas de Discriminación contra la Mujer (CEDM) y el Protocolo Facultativo de la Convención sobre la Eliminación de todas las formas de Discriminación contra la Mujer (PFCEDM), porque a pesar de la existencia de otros instrumentos internacionales que favorecen la igualdad de derechos, las mujeres siguen siendo discriminadas en todas las sociedades. (El subrayado es nuestro)

23. Según el Art. 1 de la CEDM la expresión "discriminación contra la mujer" comprende "toda distinción, exclusión o restricción basada en el sexo que tenga por objeto o por resultado menoscabar o anular el reconocimiento, goce o ejercicio por la mujer, independientemente de su estado civil, sobre la base de la igualdad del hombre y la mujer, de los derechos humanos y las libertades fundamentales en las esferas politica, económica, social, cultural y civil o en cualquier otra esfera".

24. Para el caso que nos ocupa, esta Convención reafirma que la discriminación contra la mujer comprende toda distinción de trato por razón de sexo que: (i) con intención o sin ella sea desfavorable para la mujer; (ii) sea un obstáculo para que la sociedad en su conjunto reconozca los derechos humanos de la mujer en la esfera pública y en la esfera privada; o (iii) sea un obstáculo para que las mujeres gocen y ejerzan plenamente todos sus derechos humanos.

25. De la definición de discriminación contra la mujer de la CEDM puede deducirse que cubre tanto la igualdad de oportunidades (igualdad formal) como la igualdad de resultados (igualdad de facto). Asimismo, puede deducirse que la discriminación contra la mujer abarca toda diferencia de trato (distinción, exclusión o restricción) por motivos de sexo que: a) intencionada o no intencionadamente desfavorezca a la mujer; b) impida a la sociedad en su conjunto reconocer los derechos de la mujer en las esferas doméstica y pública; o, c) impida a la mujer gozar o ejercer los derechos humanos y las libertades fundamentales de que son titulares. $(\ldots)^{\prime \prime}$

Por su parte, la Corte Interamericana de Derechos Humanos (en adelante, CorteIDH) ha defendido la no discriminación como soporte para la defensa de la violencia de género. Veamos:

- Caso del Penal Miguel Castro Castro Vs. Perú. Fondo, Reparaciones y Costas. Sentencia de 25 de noviembre de 2006.

303. Con respecto al tratamiento que deben recibir las mujeres detenidas o arrestadas, el Alto Comisionado de las Naciones Unidas para los Derechos Humanos ha señalado 
que "no deben sufrir discriminación, y deben ser protegidas de todas las formas de violencia o explotación". Asimismo, ha indicado que las detenidas deben ser supervisadas y revisadas por oficiales femeninas y las mujeres embarazadas y en lactancia deben ser proveídas con condiciones especiales durante su detención. El Comité para la Eliminación de la Discriminación contra la Mujer ha señalado que dicha discriminación incluye la violencia basada en el sexo, "es decir, la violencia dirigida contra la mujer porque es mujer o que la afecta en forma desproporcionada", y que abarca "actos que infligen daños o sufrimientos de indole física, mental o sexual, amenazas de cometer esos actos, coacción y otras formas de privación de la libertad"

- Caso González y otras ("Campo Algodonero") Vs. México. Excepción Preliminar, Fondo, Reparaciones y Costas. Sentencia de 16 de noviembre de 2009.

132. La Corte toma nota de que a pesar de la negación del Estado en cuanto a la existencia de algún tipo de patrón en los motivos de los homicidios de mujeres en Ciudad Juárez, éste señaló ante el CEDAW que "están influenciados por una cultura de discriminación contra la mujer basada en una concepción errónea de su inferioridad".

- Caso González y otras ("Campo Algodonero") Vs. México. Excepción Preliminar, Fondo, Reparaciones y Costas. Sentencia de 16 de noviembre de 2009.

164. De todo lo expuesto anteriormente, la Corte concluye que desde 1993 existe en Ciudad Juárez un aumento de homicidios de mujeres, habiendo por lo menos 264 víctimas hasta el año 2001 y 379 hasta el 2005. Sin embargo, más allá de las cifras, sobre las cuales la Corte observa no existe firmeza, es preocupante el hecho de que algunos de estos crimenes parecen presentar altos grados de violencia, incluyendo sexual, y que en general han sido influenciados, tal como lo acepta el Estado, por una cultura de discriminación contra la mujer, la cual, según diversas fuentes probatorias, ha incidido tanto en los motivos como en la modalidad de los crímenes, así como en la respuesta de las autoridades frente a éstos.

- Caso Fernández Ortega y otros Vs. México. Excepción Preliminar, Fondo, Reparaciones y Costas. Sentencia de 30 de agosto de 2010.

118. Este Tribunal recuerda, como lo señala la Convención de Belém do Pará, que la violencia contra la mujer no sólo constituye una violación de los derechos humanos, sino que es "una ofensa a la dignidad humana y una manifestación de las relaciones de poder históricamente desiguales entre mujeres y hombres", que "trasciende todos los sectores de la sociedad independientemente de su clase, raza o grupo étnico, nivel de ingresos, cultura, nivel educacional, edad o religión y afecta negativamente sus propias bases" 
En tal sentido, como se puede apreciar, la defensa del derecho fundamental a la no discriminación no es un derecho fundamental aislado en la CPP o un derecho fundamental que se encuentra de mero "adorno"; constituye, sobretodo, una pieza fundamental en los argumentos jurídicos del TC y de la CorteIDH en casos referidos a la violencia de género; por ello, es que consideramos que si bien es cierto existen avances legales sobre la materia no tendremos resultados satisfactorios si no se defiende la génesis del problema: el derecho fundamental a la no discriminación.

Al respecto, consideramos que juega un papel fundamental el Congreso de la República y/o el Poder Ejecutivo -en atribución de facultades- quienes deberán consolidar todo el marco jurídico relacionado a la materia y establecer un compendio normativo sobre violencia de género que establezca definiciones, responsabilidades, entidades involucradas, entre otros aspectos de interés.

Para ello, proponemos la creación de la Secretaría Técnica de Defensa de la Mujer, la cual podría estar adscrita a la Defensoría del Pueblo -para mantener su independencia- y que tenga como principal función la articulación con todas las entidades públicas que se encuentren relacionadas a la defensa del derecho a la no discriminación por razón de género. Se encontraría dotada de un staff de profesionales multidisciplinarios que denuncien y realicen un efectivo seguimiento, hasta su ejecución final, de todos los casos relacionados a la violencia de género.

Asimismo, sería la secretaría técnica la encargada de consolidar los esfuerzos de los planes del Estado peruano y darle viabilidad en el día a día; informando, asimismo, a través de un Observatorio Nacional de defensa de la mujer, de sus principales resultados.

Finalmente, podría generar diferentes convenios con entidades privadas nacionales e internacionales que investiguen sobre violencia de género; así como, otras funciones más que brinden la confianza y la seguridad necesaria a las mujeres peruanas.

\section{A MANERA DE CONCLUSIÓN}

Queda pendiente la efectiva puesta en marcha de un plan integral que traiga resultados efectivos frente a la violencia de género. Por nuestra parte creemos necesaria la creación de una Secretaría Técnica de Defensa de la Mujer que pueda materializar con resultados concretos, y de forma diaria, una efectiva defensa del derecho a la no discriminación. 
No creemos en una defensa del derecho a la no discriminación y a la defensa de la violencia de género desde el escritorio; tenemos frondosa normativa nacional e internacional sobre el particular, pero es momento también de hacer efectivos los derechos fundamentales "desde la cancha" y creemos que el derecho analizado en esta oportunidad es, sin duda, uno de ellos.

\section{REFERENCIAS}

Constitución Política del Perú de 1993 (1993). Edición Oficial del Congreso de la República, promulgada el 29 de diciembre. Imprenta del Congreso de la República.

Decreto Supremo N 004-2012-MIMP. “Plan Nacional de Igualdad de Género 2012 - 2017", publicado el 18 de agosto de 2012 en el Diario Oficial "El Peruano".

Decreto Supremo N ${ }^{\circ}$ 008-2016-MIMP "Plan Nacional contra la violencia de género 2016 - 2021", publicado el 26 de julio de 2016 en el Diario Oficial "El Peruano".

Resolución de la Asamblea General de las Naciones Unidas (1993) Resolución 48/104. Declaración sobre la eliminación de la violencia contra la mujer. Expedida en la 85a sesión plenaria el 20 de diciembre de 1993.

Sentencia del Tribunal Constitucional (2004) Exp N 0048-2004-AI/TC. Resolución del 1 de abril de 2005.

Fecha de recepción : 14 de setiembre de 2016

Fecha de aceptación : 10 de octubre de 2016 